\title{
Evaluation of Surgical-Navigation System in Management of Orbital Disorders
}

\author{
MAY I. EL-RASHEDY, M.Sc.; RANIA A. ABDEL SALAM, M.D. and IHAB S. OTHMAN, M.D. \\ The Department of Ophthalmology, Faculty of Medicine, Cairo University
}

\begin{abstract}
Background: Surgical navigation guidance is primarily designed to assist with surgery on bony tissues and closed spaces, it is widely used in neurosurgery and sinus surgery. And since the limited mobility of the soft tissues of the orbit, as they are tightly contained within its bony walls, stereotactic navigation may be a useful tool in orbial surgeries such as tumor excisions, biopsies, orbital wall fractures, and orbital decopmression.
\end{abstract}

Aim of Study: To evaluate whether the use of Frameless surgical navigation is useful and time efficient in removing orbital masses and repairing orbital wall fracture as known to be a helpful tool in Neurosurgery and sinus surgery.

Patients and Methods: Prospective interventional noncontrolled non-randomized case series study was coducted in Cairo Univeristy Hospitals from June 2013 to December 2014 on 15 patients with primary or recurrent post-septal orbital pathology using the Electromagnetic "FusionTM ENT Navigation System" during the surgery. Primary outcomes were assessing time efficiency through operative times (Total Time, Operating Time and Maintenance Time), extent of mass excision and fracture repair. Secondary outcomes were improvement in Hertel's readings and detecting complication related to the navigation system.

Results: The mean of maintenance time percentage compared to the total operating time was $46.7 \%$ with SD \pm 6.1 that lead to relatively longer total operating time, but as more cases were performed, it decreased gradually. Complete excision was achieved in $70 \%$ of cases. The $p$-value for improved Hertel's reading was 0.016 and only one case had significant complications.

Conclusion: Although promising results were seen in orbital wall fracture and well circumscribed orbital masses. The Surgical Navigation System cannot yet be considered the standard of care for patients with different orbital pathologies as it prolongs the total operating time. However, it is helpful and promising in complicated cases of recurrent and infiltrative masses and massive trauma, where the normal anatomical landmarks are compromised specially with the evolving updates in improving this technology.

Correspondence to: Dr. May I. El-Rashedy, The Department of Ophthalmology, Faculty of Medicine, Cairo University
Key Words: Surgical navigation - Orbital fracture - Orbital mass - Brainlab - Electromagnetic "FusionTM.

\section{Introduction}

COMPUTER-assisted surgery (CAS) with surgical navigation system was developed to enhance the accuracy and safety of brain and sinus surgery, but no particular specific system has been designed for the orbital surgery yet.

The challenge in the orbit is being a small space containing complex structures entangled by extensive fat obstructing surgical visibility and increasing the incidence of dangerous complications as; accidental entry into the brain or sinuses, double vision due to nerve or muscle injury, or afferent visual dysfunction. Using the surgical navigation system in various orbital lesions is believed to minimize this risk, as it helps in identifying anatomical landmarks and critical structures easily [1]

Real-time tracking improves the safety and can decreases the surgical duration after proper learning curve achievement. Additionally, no need to transfer the CT, MRI images to the operative site. However, limitations are due to soft-tissue shift which is of limited importance in orbital surgery as orbit is small closed space, also no secure specific orbital headset, higher expenses of that technology and need to understand the basic concepts how navigation based surgery works.

The principal concept is simply summarized as: Pre-operative CT or MRI imaging that should be sequential, non-overlapping $1 \mathrm{~mm}$ slices, to provide the 'image dataset" that enables the software to viewe it in multiple planes with a 3-D reconstruction of the orbit. Then accurate registration of the 'image dataset' with the real time surgical space for tracking system to track operative instru- 
ments in the presence of a dynamic referencing system to maintain the validity of registration and tracking during surgery.

Registration: Is the process by which preoperative image data set aligned with the real-time anatomy of the surgical space in the operating theater.

Registration is performed using either a point or surface alignment technique. The workstation/ optical digitizer or radio-frequency sensors recognize a default surgical pointer instrument within the field of view. The tip of this tool is then used to identify the real-time location of widely spaced, non-collinear surface markers on the surface of the patient's head $[2,3]$.

The co-alignment of these dataset image points with the surgical field achieves registration. Since, anatomical landmarks identifiable on the imaging and in the surgical field (e.g. nasal tip, external auditory canal, orbital margins) are co-aligned for registration.

Registration using surface alignment uses complex mathematical algorithms to co-align the surface of the patient's head in the operating theater with the surface of the image dataset. A Laser beam is used to the sight of the optical digitizer to delineate the periorbital and forehead regions of the scalp. Co-alignment of the thousands of surface points identified by the Laser and the surface contours of the image dataset enables registration, manual addition of another 10 or more point from all quadrants of the scalp using the default pointer further refines the accuracy of this technique $[2,3]$

The accuracy of registration must be confirmed with visual checks. The computer monitor shows the pre-operative image data set (usually in axial, coronal and sagittal planes with a 3D reconstruction view). Known landmarks on the dataset are identified in the surgical space using the default pointer tool (e.g. globes, orbits, external auditory meatus, and tragus). The radiological and real-time anatomical landmarks should coincide exactly. If there are discrepancies, the registration process should be repeated [3].

Tracking: Could be either optoelectronic or electromagnetic. Optoelectronic tracking uses infrared light for the instrument localization. Active instruments connected to the navigation system with a wire or passive cordless systems use markers that are seen by the infrared camera.

On the other hand, electromagnetic tracking uses radio-frequency sensors that detect electro- magnetic field variations caused by the instruments or patient movement. This system is contraindicated in patients with pacemakers. Also, metallic surgical instrumentations and electromagnetic equipment in the room may interfere with the electromagnetic field.

\section{Material and Methods}

The study took place from June 2013 to December 2014, on 15 patients with post septal orbital lesion whether primary or recurrent, the orbital fracture not involving the orbital rim. Patients were recruited from the outpatient oculoplastic clinic of Kasr Al-Aini Hospital, Cairo University. Patients with preseptal orbital masses, or fracture involving the orbital rim were excluded from the study.

I- Preoperative evaluation: Was done including complete history and ophthalmological examination including BCVA, Hertel's Exophthalmometry, ocular motility in all six cardinal positions, together with patient Photography.

II- Imaging studies: CT Orbit in fractures and MRI orbit with Intravenous contrast in orbital lesions were done using brain lab protocol (in which scans were $1.0-1.5 \mathrm{~mm}$ slices in CT, 1.5 $2.5 \mathrm{~mm}$ in MRI, Axial non-overlapping and contiguous slices that scan the whole head (Include the hard palate, the tip of the nose, the ears, the top of the head). Scans should be parallel \& perpendicular to the cantho-meatal line and coronal scans extended from orbital rim to the sella to allow full and centerralized orbital scanning.

III- Intraoperative management: Informed consent was taken from the patients or their legal guardians for surgery using the Electromagnetic "FusionTM ENT Navigation System" (Medtronic, Florida, USA), The System consisted of:

- StealthmergeTM ENT System software: A computer station where the preoperative images data from CT and MRI were integrated and automatically merged giving advanced 3D matching algorithms.

- The field generating magnet: Was mounted to the corner of the operating room table near the head of the patient. The magnet is connected to the signal generator within the computer station and generates the magnetic field required for tracking.

- Head Tracker kit: It consists of a silicone head strap and contact pads. See Fig. (1).

- The standard set of instruments: Includes a registration probe, straight suction, $90^{\circ}$ curved suction, $70^{\circ}$ curved suction and a straight probe. 
Setting up the machine: The silicone head strap and contact pads were inspected for cuts, cracks or deterioration before each use. The intended mounting area was sterilized then dried to avoid pad slippage. The silicone strap and pads were then placed under the patient's head around the occipital region and centered laterally without distorting the ears. The strap length was roughly equal on the left and right sides with even tension to prevent lateral drift during surgery. The headset sufficiently stabilized to be resistant to slippage.
The marker coil that connects the headset to the machine was then attached.

Registration: Was done to correlate the patient's head position on the operating table with the 3-D image dataset on the computer monitor. The registration probe was registered on the marker coil then tracked over the bony prominences starting with the tip of the nose to nasal bridge and superior orbital rim bilaterally. See Fig. (1).
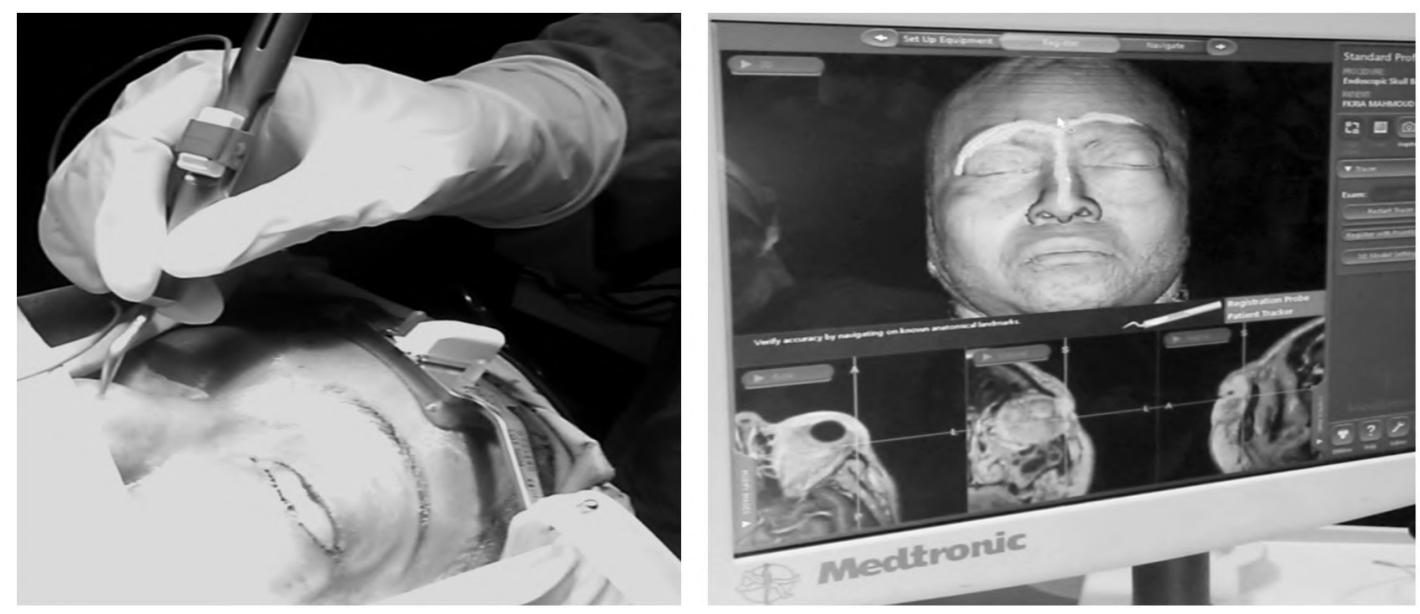

Fig. (1): Process of registration and checking accuracy.

Checking the accuracy by placing the registration probe over known surface anatomic landmarks as the zygomatico-orbital, nasal ridge and detect the probe simultaneously over the displayed screen. If there was any discrepancy, the registration process was repeated. After this initial tracking process and verification, other surgical instruments did not require additional calibration as the computer system automatically detects the instruments being used. The system can track three instruments simultaneously. The system then simultaneously displays the axial, coronal, and sagittal locations of each instrument in use.

Surgical approach:The surgical approach was selected for each patient according to the location of the. The choice of the incision was based on the site that gives the nearest access, best visualization of the mass together with least expected tissue injury and best cosmetic results. We used both trans-cutaneous and trans- conjunctival approaches and sometimes were combined with endoscopic trans-nasal in masses extending from the nasal sinuses with the help of ENT surgeon.

During every step in the surgery real time tracking was ensured using any of the instruments mentioned above for precise and accurate localization of lesion.

The degree of excision or repair: Was determined by the impression of the surgeon during the surgery and by the postoperative pathological examination of the margins of the mass. The level of excision was classified as complete (no surgical, pathological and radiological visible residual mass) incomplete (gross intraoperative residual, positive pathology for mass margins). While in repair of orbital fracture was defined as either complete or incomplete by closing the posterior edge of fracture intra-operatively.

Operative times: These were defined as Total Time in OR (time interval between a patient entering and exiting OR), actual Operating Time (time interval between the surgical incision and dressing completion) and Maintenance Time, (time needed for the initial machine setup together with any intraoperative interruption than required resetting of the machine).

IV- Postoperative management: Masses were sent for pathological examination after the surgery. Patients were followed-up on first postoperative 
day, then after one week, then after 1,3 and 6 months intervals complete ophthalmic examination Hertel's exophthalmometer and checking for any complications or disease recurrence and repeating the imaging studies if needed.

\section{Statistical methods:}

Data was analyzed using windows statistical software. Descriptive statistics were calculated and numerical data were summarized as mean \pm $\mathrm{SD}$ while categorical data were summarized in percentages. Wilcoxon Signed-Rank Test was used to compare numerical data between preoperative and postoperative measurements to calculate $p$ value in which it was considered to be significant if $<0.05$. Correlation between ordinal variables was done using Chi-square and correlation.

\section{Results}

The study took place at Cairo University Hospitals, Kasr Al-Aini. It included fifteen patients (Table 1) who underwent orbital surgery using the intraoperative frameless navigation guidance system.

Table (1): Summary for included cases in the study.

\begin{tabular}{|c|c|c|c|}
\hline Case & Age/Sex & Imaging CT/MRI & Pathology/Diagnosis \\
\hline 1 & $38 \mathrm{M}$ & Inferonasal, well circumscribed, extraconal mass & Cavernous hemangioma \\
\hline 2 & $5 \mathrm{M}$ & Well circumscribed superiotemporal extraconal & Lacrimal gland cystadenoma \\
\hline 3 & $38 \mathrm{M}$ & Well-circumscribed superio-nasal intraconal mass & $\begin{array}{l}\text { Orbital cyst with nonspecific } \\
\text { inflammatory reaction }\end{array}$ \\
\hline 4 & $29 \mathrm{~F}$ & Superior, well circumscribed, intraconal mass & Cavernous hemangioma \\
\hline 5 & $47 \mathrm{M}$ & Superio-temporal, well circumscribed, intraconal mass & Cavernous hemangioma \\
\hline 6 & $7 \mathrm{M}$ & Well circumscribed intraconal heterogeneous cystic lesion & $\begin{array}{l}\text { Orbital cyst with nonspecific } \\
\text { inflammatory reaction }\end{array}$ \\
\hline 7 & $48 \mathrm{~F}$ & $\begin{array}{l}\text { Extraconal, intraconal mass invading MR and orbital apex, } \\
\text { extending from ethmoidal and sphenodal sinuses }\end{array}$ & Aspergillus invasive fungal sinusitis \\
\hline 8 & $20 \mathrm{~F}$ & Extraconal, intraconal mass invading from ethmoid, maxillary & Aspergillus invasive fungal sinusitis \\
\hline 9 & $37 \mathrm{~F}$ & Heterogeneous infiltrating intra and extraconal mass & $\begin{array}{l}\text { Grade II malignant peripheral nerve } \\
\text { sheath tumor }\end{array}$ \\
\hline 10 & $59 \mathrm{~F}$ & Ill-defined mass infiltrating medial and inferior compartments & Orbital inflammatory disease \\
\hline 11 & $34 \mathrm{M}$ & Medial and inferior wall fractures with MR entrapment & Orbital wall fracture \\
\hline 12 & $16 \mathrm{M}$ & Inferior orbital wall fracture with IR entrapment & Orbital wall fracture \\
\hline 13 & $14 \mathrm{M}$ & Inferior orbital wall fracture with IR entrapment & Orbital wall fracture \\
\hline 14 & $23 \mathrm{M}$ & Inferior and medial orbital wall fractures & Orbital wall fracture \\
\hline 15 & $28 \mathrm{~F}$ & Orbital fat hypertrophy, MR enlargement & Thyroid eye disease, fat tissue \\
\hline
\end{tabular}

Results showed that in $70 \%$ of cases complete surgical removal (excisional biopsy) of the lesion was achieved, while in $30 \%$ of cases incomplete removal of the lesion was done (debulking) (case no. $7,8,10$ ). The surgical navigation system appeared to be useful in complete excision of all well circumscribed orbital lesions and one of the illdefined lesions through proper reaching their posterior extent without injury to the nearby structures. This was further assisted by the fixed nature of orbital surgical targets that showed no shift during surgery and the continuous real-time intraoperative tracking, taking in consideration not to aspirate or open any cystic component of the lesions to maintain this fixed target. However three out of four ill-defined orbital lesions could not be completely excised with gross residual, despite using combined transnasal and transorbital approaches. This was due to the infiltrative nature of the disease and adhesions to neurovascular structures as in orbital inflammatory disease and invasive aspergillus fungal sinusitis, those cases did not have any postoperative complications during the period of follow-up related to endoscopic sinus surgery like muscle injury or optic nerve trauma.

In all orbital fracture cases the posterior extent of the fracture was precisely localized, followed by proper sizing and fitting of the implant (Medpore) over the defect. On completion of reconstructive plate placement, the probe was successfully utilized to confirm plate positioning in all cases. None of them had any postoperative limitation of ocular motility or defective globe position during the period of follow-up with complete resolution of preoperative restrictive ocular motility. The case of TED had successful two wall decompression.

The change in Hertel's exophthalmometer readings in diseased eyes was statistically significant from the pre-to postoperative measurements with $p$-value 0.016 . However, there was no clear evidence that this change is related to the use of surgical navigation as this could be due to the mere surgical procedure. 
There was no mortality in our study, Complications were mostly transient in form of limitation of ocular motility, anisocoria those resolved between one to 3 months postop. Permanent complete ptosis occurred in one case only no. 4.

Concerning the calculated different operative times in minutes there was increase in total operating time due to added machine maintenance time which ranged from $23-45 \mathrm{~min}, \mathrm{SD} \pm 6.8 \mathrm{~min}$; however there was a negative linear correlation in the maintenance time with cases towards the end of the study. Fig. (2).



Fig. (2): Linear decline in maintenance time the cases in the graph were arranged according to which was operated first.

The actual and maintenance operating time percentages from the total operating time were calculated and showed that the maintenance time $\%$ ranged from $25 \%$ to $68 \%$ with mean of $47 \%$ of the total operating time and SD $\pm 13.8 \%$.

The actual operating times were compared in different type's orbital lesions to detect lesions with shortest and longest operative times. The actual operating time in well-defined lesions mean $28.6 \mathrm{~min}, \mathrm{SD} \pm 14.4$ in orbital fractures mean $40 \mathrm{~min}$, $\mathrm{SD} \pm 12$ and in ill-defined lesions mean $96.2 \mathrm{~min}$, $\mathrm{SD} \pm 32.4$. The long time in the latter lesions is probably due to their infiltrating nature that makes proper and safe dissection time-consuming.

\section{Discussion}

In our study the intraoperative time was initially longer with using navigation guidance. However, it continually down trended with sequential cases towards the end of the study. This was going with Chris et al., who found that although initially longer surgical time, actual operating times consistently decreased with each subsequent case until they are shorter than surgeries performed without navigation
[4]. Similarly Yang et al., found that the use of navigation system in neurosurgery resulted in shorter operative time, less blood loss and decrease radiation exposure [5]

Initial prolongation that we found was attributed to the machine setup time together with intraoperative difficulties met during the learning curve. For example, the multiple attempts of registration at the beginning of the surgery to ensure accuracy and the repeated slippage of the silicone head strap and pad during the operation, that led to the stoppage and repeating all steps of replacing it and repeating the registration. Additionally, sometimes the field generating magnet moved so that the surgical instruments are no longer inside the electromagnetic field and hence could not be detected and tracked. This warranted the repositioning of the field generating magnet so that the computer system automatically could detect the instrument in use. Our conclusion was the same as Lee, Miller et al., who found that commonly encountered disadvantages of surgical navigation include learning curve, machine setup times, expense and equipment availability $[6,7]$

These difficulties led to a relative increase in the total operative time. This increase was mainly in the maintenance time which was up to $46.7 \%$ of the total surgical time (i.e. nearly half the time the patient stayed in the operating room). However, there was a consistent decremental trend in the maintenance times in sequentially performed cases due to the learning curve. These results differ from the study conducted by Chris et al., where the maintenance time percentage of total operating time ranged from $22 \%$ to $65 \%$ with mean $34 \%$ and the authors did not see any consistent trend in the maintenance times in sequentially performed cases. This could be due to the use of auto-registration mask which markedly decreases the incidence of intraoperative machine difficulties [4]. Unfortunately, this technology was not available in our market during the time of the study.

Collectively in our study we completely excised the mass in $70 \%$ of cases. However, in a study carried by Hodaj et al., only complete excision could be achieved in five cases $(29 \%)$ out of seventeen cases although they used orbitotomy approach [8]. In our study, the navigation guidance did enhance the confidence of intraoperative debridement and localization of the extent of lesions through viewing real-time images of axial, coronal and sagittal planes simultaneously. This reduced unnecessary surgical manipulation and eliminated dangerous blind dissection near critical structures 
and allowed better debulking in masses that couldn't be completely removed. Also in brain surgery, Hegazi found that intraoperative anatomical localization was accurate to within $1.21 \mathrm{~mm}$ and remained stable during the operative procedure. However, the so-called brain shift that may increase intraoperative inaccuracy is inapplicable when treating patients with orbit lesions due to the limited mobility of the soft tissues of the orbit, as they are tightly contained within its bony walls as mentioned before [9].

Orbital fracture cases in this study were selected as isolated orbit fractures with no orbital rim or reference points displacement that could impair the intraoperative accuracy (in such conditions, the surgeon should incorporate the degree of displacement into preoperative measurements to prevent skewed intraoperative measurements [10]), this helped in proper repair of fracture and placement of the implant with assistance of the surgical navigation and eliminated the cost of for postoperative CT scans, and long term post-operative complications as persistent diplopia. This in accordance with Brian et al., who stated that intraoperative implant localization, highlights an advantage of this technology for situations where the surgeon may desire a postoperative scan. In such situations, intraoperative image guidance potentially eliminates the necessity of obtaining a postoperative CT scan, especially that Medpore implants which cannot be detected with CT, together with avoiding the cost of the scan and associated radiation exposure to the patient [10].

Persistent postoperative diplopia had been reported in other studies where navigation was not used such as Ceylan et al., who reported $20 \%$ of treated cases had persistent diplopia [11]. This means that using the navigation can give better results however, cannot be accurately compared to the current study as the number of our cases is few and nature of fractures was variable in the other study.

Finally, both inferior and medial wall decompression was done in the case of thyroid eye disease, the surgical navigator system helped in localizing important structures like infra-orbital nerve and vessels and in extending decompression more posteriorly without injury to structures at the orbital apex. However; it should also be elaborated that one case is not enough to judge the efficiency of this system in similar cases.

None of the included cases showed deterioration of the postoperative BCVA throughout the follow- up period. This highlights the safety of the surgical navigation system that could provide complete protection of the optic nerve through proper operative technique.

Only one case developed permanent complications due to improper intraoperative hemostasis that led to the formation of orbital hematoma with subsequently lost elevation movement of the globe, complete ptosis and loss of sensation. The hematoma was thought to compress 3 rd nerve branches supplying superior rectus and levator muscle as well as supraorbital nerve. Failure of improvement following hematoma absorption was related to the fact that actual nerve injury had already happened. The known incidence of this complication is very low as found in a study by Maurer et al., in which only two cases had postoperative orbital hemorrhage in which patients were on blood thinners too [12].

Other temporary postoperative complications that resolved during the period of follow-up and was contributed to postoperative edema occurred in 2 cases that had a limitation in ocular motility and one instance with anisocoria.

The limitations of this study include the small sample size, discrepancy in the orbital diseases included as well as the absence of control group. Consequently, the efficiency of the surgical navigation system could not be evaluated in each disease and it was hard to establish its time efficacy and outcome compared to conventional non-system supported surgery.

More researchers are recommended with a larger sample size of each orbital disease together with the control group for proper studying of further benefits and drawbacks of the surgical navigation system in orbital surgery.

\section{References}

1- KLIMEK L., WENZEL M. and MOSGES R.: Computerassisted orbital surgery. Ophthal. Surg., 24: 411-417, 1993.

2- SCHULDER M., MALDJIAN J.A., LIU W.C., et al.: Functional image-guided surgery of intracranial tumors located in or near the sensorimotor cortex. Journal of Neurosurgery, 89 (3): 412-8, 1998.

3- BUCHOLZ R., MARZOUK S. and LEVY A.: Image guidance and the operating microscope: Stealth and neural navigation. Chapter 28 in Advanced Neurosurgical Navigation Eds. E. Alexander III, R.J. Maciunas (p345 -355). Thieme Medical Publishers Inc. New York, 1999.

4- CHRIS Y. and ALON K.: Stereotactic Navigation with a Registration Mask in Orbital Decompression Surgery: 
Preliminary Results. Ophthalmic Plastic Reconstructive Surgery, Vol. 31, No. 6, 440-444, 2015.

5- ALEXANDRA J. YANG, et al.: Image Guided Neurosurgery, Elsevier, 350, 2015.

6- LEE K.Y., ANG B.T., NG I., et al.: Stereotaxy for surgical navigation in orbital surgery. Ophthalm Plastic Reconstructive Surgery, 25: 300-2, 2009.

7- MILLAR M.J. and MALOOF A.J.: The application of stereotactic navigation surgery to orbital decompression for thyroid-associated orbitopathy. Eye (Lond), 23: 1565$71,2009$.

8- HODAJ I., MURAT K., ENGINE G., et al.: The Use of Neuronavigation and Intraoperative Imaging Systems in the Surgical Treatment of Orbital Tumors. Turk Neurosurg, Vol. 24, No. 4, 549-557, 2014.
9- HEJAZI N.: Frameless image-guided neuronavigation in orbital surgery: Practical applications, Neurosurg Rev., 29: 118-122, 2006.

10-BRIAN T., CHRISTOPHER C., NEIL T., et al.: Utilization of Computed Tomography Image-Guided Navigation in Orbit Fracture Repair. The Laryngoscope, 123: 13891393, 2013.

11- CELYAN O.M., UYSAL Y., MUTLU F.M., et al.: Management of diplopia in patients with blowout fractures, Indian Ophthalmol., 459-464, 2011.

12- MAURER P., CONARD-HENGERER I., HOLLSTEIN S., et al.: Orbital hemorrhage assaociated with orbital fractures in geriatric patients on antiplatelet or anticoagulation therapy, Int. J. Oral Maxillofac. Surg. Dec., 42 (12): 1510-1514, 2013.

\section{تقييم نظام الملاحة العصبية فى علاج أمراض الحجاج}

يحتوى حجاج العين على مكونات تثريحية أساسية اللوظيفة الفسيولوجية اللوئية، معالجة الصور، حركية العين، ومظهر المريض وحيث أنها عبارة عن مساحة مغلقة صغيرة مما يجعل العملية الجراحية داخلة صعبة مع ارتفاع مخاطر الإصابة لتلك المكونات الهامة.

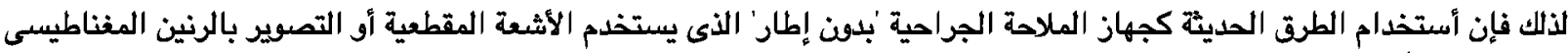

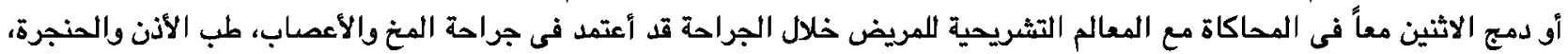
جراحة الوجه والفكين لكنه لم يعتمد بعد فى جراحات العجاج.

الفرض من هذه الدراسة: هو تقييم ما إذا كان استخدام جهاز الجراحة الملاحية فى أمراض الحجاج المختلفة يوفر ما يكفى من التطبيق، الدقة، الكفاءة وتوفير الوقت مما يجعل منه أداة مفيدة فى هذه النوان النوعية من الجراحات.

مع توفر هذه التكنولوهيا يمكن الجراحين وئية الادوات الجراحية فى الوقت الحقيقى الجراحة ميدانيا بناءعلى الصور عالية الدقة المأخوذة قبل الجراحة.

وقد أدرجت خمس وأعتمد تصميم الدراسة على سلسة من الحالات التى تم اختيارها بطريقة غير عشوائية للتدخل الجراحى عشرة حالة

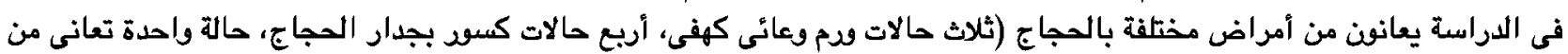
مرض الحجاج الناتج عن الغدة الدرقية، حالتان من إلتهاب الجيواب الأنفية الفطرية الذى غزا الداني الحجاج وخمس حالات أودام بالحجاج).

ومن ثم تم حساب زمن الجراحة الكلى وزمن الجراحة الفعلى وزمن التشغيل ومقارنتها ـ فأظهرت النتائج أن النسبة المئوية لزمن التشفيل

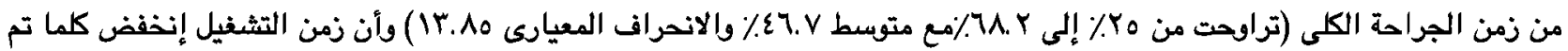
إجراء المزيد من الحالات بسبب المنحنى التعليمى.

توصلت الدراسة إلى أن نظام الجراحة الملاحية يعد أداة عظيمة خلال الجراحة وعلى الرغم من ذلك فإنه لا ينبفى أن يكون بديلاً عن المعرفة

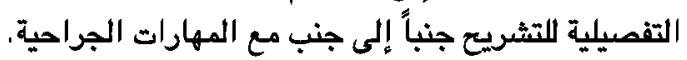

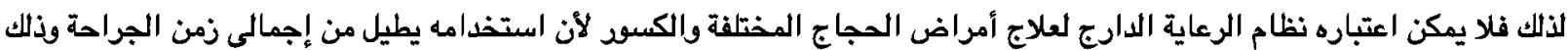

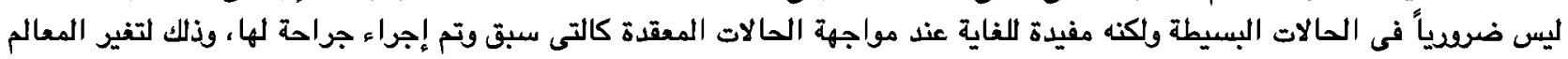
التشريحية الحجاج. 